\title{
Development of the Irrational Belief Test for Nurses (IBTN): Examination of Reliability and Validity
}

\author{
Takashi Ohue1, Michiko Moriyama², Takashi Nakaya ${ }^{3}$ \\ ${ }^{1}$ Department of Nursing Science, Faculty of Health Science, Hyogo University, Hyogo, Japan \\ ${ }^{2}$ Division of Nursing Science, Graduate School of Health Sciences, Hiroshima University, Hiroshima, Japan \\ ${ }^{3}$ Faculty of Health and Welfare, Prefectural University of Hiroshima, Hiroshima, Japan \\ Email: ohue@hyogo-dai.ac.jp, morimich@hiroshima-u.ac.jp, nakaya@pu-hiroshima.ac.jp
}

Received 22 December 2014; accepted 8 March 2015; published 13 March 2015

Copyright (C) 2015 by authors and Scientific Research Publishing Inc.

This work is licensed under the Creative Commons Attribution International License (CC BY). http://creativecommons.org/licenses/by/4.0/

(c) (7) Open Access

\begin{abstract}
[Purpose]: The purpose of this study is to develop irrational belief test for nurses, and to examine reliability and validity. [Method]: In study 1, The Irrational belief test for nurses was developed based JIBT-20 (mori et al., 1994) of previous studies. And for the nurse ( $\mathrm{N}=96,5$ male, 91 female), carried out preliminary investigation, created the provisional version of the Irrational belief test for nurses, and examined factor structure and internal consistency. In study 2 , for the nurse $(\mathrm{N}=$ 541, 21 male, 520 female) examined validity based on JIBT-20 (Japanese Irrational Belief Test), MBI (Maslach Burnout Inventory), ATQ-R Japanese version (Automatic Thoughts QuestionnareRevised), and for the nurse ( $\mathrm{N}=91,3$ male, 88 female) examined a test-retest reliability four weeks afterward before long. [Result]: As a result of the explanatory factor analysis by a maximum likelihood estimation and promax rotation, 28-item 7 factors were extracted and was named a "patient belief", "self-expectation", "avoidance", "self-inhibition", "Ethical blame", "helplessness", and "dependence". Moreover, as a result of conducting confirmation factor analysis, the hypothetical model obtained by explanatory factor analysis fitted (GFI $=0.89$, AGFI $=0.86$ ). About the reliability of the measure, a Cronbach's alpha coefficient is $0.68-0.82$, and a test-retest reliability is 0.64 and reliability is affirmed. About construct validity was checked correlation with JIBT-20, and about criterion validity was checked the correlation with MBI and ATQ-R Japanese-translation version. [Conclusion]: It is suggested that reliability and validity are verified and the irrational belief test for nurses is a useful measure. The developed test can be used to measure the irrational belief in the context of burnout in nurses.
\end{abstract}

\section{Keywords}

Nurse, Irrational Belief, Cognitive Behavioral Therapy 


\section{Introduction}

Ellis conceptualized the belief system represented by the word "must," which is related to depression, and an unfounded, but absolute and ideological concept, defined as "irrational belief" [1]. An example of irrational belief is that one must be loved and approved by everyone in order to be happy or to have a sense of self-worth. Balever reported the relationship between burnout of nurses and irrational belief [2]. However, Balever used the Maladaptive Cognitive Patterns Scales for the measurement of an irrational belief. This is a general measurement tool that is not only used for nurses but also for other subjects in the context of everyday life. Then, Ohue et al. found that a cognitive model of a relationship between stress and burnout in nurses using "irrational belief" and "automatic thoughts" was a buffering factor. By cognitive behavior therapy, changing cognitive factors, such as a nurse's irrational belief and automatic thoughts, has suggested a possibility of leading to reduction of a burnout [3]. In order to assess "irrational belief”, Ohue et al. used Japan Irrational Belief Test-20 (hereinafter, JIBT-20) suggested by Mori et al. [4]. However, Mori et al. have indicated that the irrational belief which is induced in a particular situation outside the ordinary life may not be assessed with JIBT-20 [4]. In fact, question items in JIBT-20 have been made on the basis of daily life setting such as "a thief deserves to be punished" or "one who committed murder should be charged with the death penalty". These "irrational beliefs" are not "irrational beliefs" for predicting a nurse's burnout. This consideration leads us to develop the irrational belief scale for nurses. On the other hand, it is thought that questions which cover the entire nursing settings would be necessary in order to design the scale, considering that "irrational belief" is a reaction style which affects individuals regardless of the settings or situations [5]. Moreover, an irrational belief is also promoted indirectly by the environmental context [1]. This implies that if a reaction style, that is an irrational belief gets promoted within the nursing context, it could indicate that the nurses might also have developed such beliefs.

As mentioned above, the index which needs to apply the cognitive approach which aimed at a cognitive correction to reduction of a nurse's burnout therefore by which evaluate a nurse's irrational belief is needed.

In the previous study in Japan, Kawamura et al. indicated that there is irrational belief common among teachers, which is induced by their own experiences rather than their personal quality, and developed a belief scale which is specific for teachers [6]. In addition, there are other scales which measure irrational beliefs such as scales for "irrational belief regarding foods" [7]-[9], "irrational belief in sportive situations" by Ito et al. [10], "irrational belief in human relations of junior high school students" by Honda et al. [11], and "belief regarding body shape and diet" by Matsumoto et al. [12], but there is no scale which assesses irrational belief in nurses. Therefore, it is necessary to develop the irrational belief test for a nurse. It is thought that development of a test which assesses irrational belief in nursing practice might be useful to evaluate preventive interventions for burnout in nurses and would be very meaningful.

Consequently, the objective of this study is to develop the Irrational Belief Test for Nurses (hereinafter, referred to as IBTN) and assess reliability and validity.

\section{Study 1 (A Pilot Study)}

1. Purpose: Collect the description about irrational belief for nurses, develop irrational belief test for nurses, and examine the internal consistency of a test.

\section{Method}

The process of developing the IBTN draft.

We carried out the following: 1) preparation of item pool and 2) investigations on the factor structure and internal consistency as well as correction of the items.

1) Preparation of the item pool

The item pool was prepared by 6 experts, referring to 20 items from JIBT-20 as in the previous study [4], a belief scale specific to junior high school teachers developed by Kawamura et al. [6], a scale measuring job stressors of clinical nurses (Nursing Job Stressor Scale: NJSS) by Higashiguchi et al. [13], and a scale for irrational belief in junior high school teachers by Doi et al. [14]. At that time, situations described in the questions of JIBT-20 were replaced by nursing settings while verbs remained unchanged in those sentences. The categories included sub-catagories of JIBT-20 [4], namely, "self-expectation”, "dependence”, "ethical blame”, "problem avoidance", and "helplessness". Moreover, considering that 5 factors including "self-incompetence”, "distrusting others", "fear of failure", "self-inhibition ", and "students' image idealistic for teachers" have been extracted in the irrational belief scale in junior high school teachers, two more categories, "patient belief" and 
"self-inhibition", were added as irrational beliefs specific to nurses in this study. A total of 7 subconcepts were established, and 63 items were included.

2) Investigations on the factor structure and internal consistency and determination of items (implementation of a pilot study)

a) Subjects: The subjects included a total of 96 nurses consisting of 5 males and 91 females with the age of $37.0 \pm 7.9$ years. The pilot study was conducted using a questionnaire sheet in nurses working in acute-phase hospitals, home medical care facilities, or in nursing homes in Japan. The study was conducted between April 2009 and May 2009.

b) Investigation content: Sixty three items created in 1) were used as the "IBTN draft". In IBTN, how much the description in each question represents one's feeling was evaluated by the 5-point method (5: feel exactly the same way; 1: do not feel the same way at all).

3) Analysis

a) Item analysis: the ceiling effect, the floor effect, each correlation analysis between items, and I-T correlation was computed.

b) Factor analysis: A factor and the item which a factor and a question item did not move were chosen in a factor analysis.

c) Examination of reliability: The Cronbach's alpha coefficient of the whole questionnaire and each factor was computed for the check of internal consistency.

3. Results

1) The result of item analysis and explanatory factor analysis

The items were analyzed; 15 out of 63 items in total in IBTN were excluded, and the remaining 48 items were included in the factor analysis set. Exploratory factor analyses were performed by varimax and promax rotations of principal factor analysis and maximum likelihood estimation. The items with factor loading of 0.30 or below were excluded. As a result, IBTN was created using 7 factors with 28 items which had been consistent in all factor analyses. The 7 factors extracted by the analyses were characterized as follows. The first factor indicates beliefs for patients as represented by views such as "The patient should tackle everything positively"; therefore, the first factor is named "patient belief". The second factor indicates high expectations for their behaviors and potential as represented by the view "Questions asked by a patient and a family must always be answered"; therefore, the second factor is named "self-expectation". The third factor indicates avoidance of or escape from the job as represented by the view "It is natural to want to abandon work that requires judgment, attentiveness, a sense of responsibility, etc" therefore, the third factor is named "avoidance". The forth factor indicates self-inhibition and obedience as represented by the view "One must consider the patient's welfare, when there is a human relations problem with the doctor"; therefore, the forth factor is named "self-inhibition". The fifth factor indicates ethical blame for the view "Threatened medical staff should resign"; therefore, this is named "ethical blame". The sixth factor indicates helplessness in control of emotions such as psychological unrest as represented by the view "People who cannot provide patients with emotional support are useless"; it is named "helplessness". Finally, the seventh factor is associated with "dependence" which indicates necessity for being dependent on others as represented by the view "If those who talk about their thoughts or feelings about work and can provide advice are not working in the same location, I will be troubled". Table 1 summarizes the extracted factors, the factor loadings for each item, $\alpha$-coefficient, and inter-factor correlations.

2) Confirmation of internal consistency

In order to affirm internal consistency, the alpha coefficient was calculated for the IBTN subscales used to measure the irrational beliefs in nurses. The factor-wise values were as follows: "Patient belief" $\alpha=0.81$, "Self expectation" $\alpha=0.73$, "Avoidance" $\alpha=0.69$, "Self inhibition" $\alpha=0.71$, "Ethical blame" $\alpha=0.78$, "Helplessness" $\alpha=0.82$, and "Dependence" $\alpha=0.68$. Therefore, on the basis of the above values, we considered the internal consistency as verified. Table 1 further shows the results of these calculations.

\section{Study 2 (Actual Study)}

1. Purpose: It is examination of the validity irrational belief test for nurses created in Study 1, and examining test-retest reliability.

2. Method

1) Subjects: The questionnaires were distributed to 700 nurses at 5 hospitals and 550 replied (collection rate 
Table 1. Result of explanatory factor analysis of IBTN (Maximum likelihood estimation/Promax rotation).

\begin{tabular}{|c|c|c|c|c|c|c|c|c|}
\hline & \multicolumn{6}{|l|}{ Question item } & \multicolumn{2}{|c|}{ Factor loading } \\
\hline & I: "Patient belief" $(\alpha=0.81)$ & & & & & & & \\
\hline 37 & The patient should be mentally composed during hospitalization. & 0.85 & -0.26 & -0.11 & -0.05 & 0.02 & 0.02 & 0.09 \\
\hline 38 & The patient should tackle everything positively. & 0.82 & 0.18 & 0.05 & -0.09 & -0.09 & -0.07 & 0.06 \\
\hline 36 & The patient must always desire treatment. & 0.77 & 0.00 & -0.16 & 0.09 & 0.05 & 0.07 & -0.17 \\
\hline 52 & $\begin{array}{l}\text { It is natural for a patient receiving positive treatment to recover. } \\
\text { I: “Self-expectation” }(\boldsymbol{\alpha}=\mathbf{0 . 7 3})\end{array}$ & 0.43 & 0.18 & -0.04 & 0.01 & -0.05 & 0.18 & 0.16 \\
\hline 47 & Questions asked by a patient and a family must always be answered. & 0.04 & 0.78 & 0.10 & 0.09 & 0.07 & -0.10 & -0.11 \\
\hline 48 & One must work beyond one’s capability. & 0.02 & 0.74 & 0.12 & 0.12 & 0.01 & -0.02 & 0.06 \\
\hline 63 & Patients should be offered mental care even in one's spare time. & -0.19 & 0.54 & -0.05 & -0.15 & 0.09 & 0.15 & 0.15 \\
\hline 43 & Medical equipment must be mastered. & 0.00 & 0.39 & -0.18 & -0.01 & -0.12 & 0.30 & 0.13 \\
\hline & III: “Avoidance" $(\alpha=0.69)$ & & & & & & & \\
\hline 12 & $\begin{array}{l}\text { When there is insufficient time to finish work, it is natural to want } \\
\text { to abandon it. }\end{array}$ & -0.13 & 0.10 & 0.74 & -0.19 & -0.08 & 0.04 & 0.08 \\
\hline 11 & When talking, it is safe to talk only about uncomplicated subjects. & -0.09 & 0.05 & 0.72 & 0.16 & -0.10 & 0.05 & -0.16 \\
\hline 13 & It is not approaching the patient who thinks that I dislike. & -0.01 & -0.35 & 0.46 & 0.10 & 0.02 & 0.06 & 0.12 \\
\hline 9 & $\begin{array}{l}\text { It is natural to want to abandon work that requires judgment, } \\
\text { attentiveness, a sense of responsibility, etc. }\end{array}$ & -0.02 & 0.11 & 0.44 & -0.12 & 0.03 & 0.10 & 0.18 \\
\hline & IV: "Self-inhibition" $(\alpha=\mathbf{0 . 7 1})$ & & & & & & & \\
\hline 34 & $\begin{array}{l}\text { One should obey examination and treatment instructions bearing } \\
\text { the patient in mind }\end{array}$ & -0.01 & 0.06 & 0.01 & 0.96 & -0.03 & -0.05 & 0.01 \\
\hline 35 & One should obey the doctor's orders unselfishly. & -0.10 & 0.02 & -0.16 & 0.73 & -0.10 & 0.22 & -0.03 \\
\hline 30 & $\begin{array}{l}\text { One must consider the patient's welfare, when there is a human } \\
\text { relations problem with the doctor. }\end{array}$ & 0.03 & 0.02 & 0.08 & 0.40 & 0.17 & -0.01 & 0.13 \\
\hline 33 & All the patient's complaints should be considered. & 0.09 & 0.00 & 0.06 & 0.34 & 0.04 & 0.07 & 0.00 \\
\hline & V: "Ethical blame” $(\alpha=0.78)$ & & & & & & & \\
\hline 2 & Threatened medical staff should resign. & -0.07 & -0.01 & -0.17 & 0.05 & 0.93 & 0.14 & 0.04 \\
\hline 1 & Nurses who cannot perform their duties should resign. & -0.01 & 0.14 & -0.08 & -0.08 & 0.80 & 0.04 & -0.07 \\
\hline 3 & Threatened patients should leave the hospital. & 0.06 & 0.09 & 0.42 & 0.03 & 0.46 & -0.15 & -0.05 \\
\hline 5 & Rebellious subordinates should resign from the hospital. & 0.08 & -0.14 & 0.24 & -0.05 & 0.43 & 0.05 & 0.03 \\
\hline & VI: “Helplessness” $(\alpha=0.82)$ & & & & & & & \\
\hline 55 & $\begin{array}{l}\text { People who cannot provide patients with emotional support are } \\
\text { useless. }\end{array}$ & -0.01 & 0.14 & 0.07 & 0.08 & 0.00 & 0.76 & -0.01 \\
\hline 56 & People who cannot make progress in nursing are useless. & 0.14 & 0.09 & 0.11 & 0.04 & 0.04 & 0.70 & -0.01 \\
\hline 54 & Nurses who once lose trust spoil everything. & -0.03 & -0.15 & -0.04 & 0.09 & 0.14 & 0.63 & 0.13 \\
\hline 57 & $\begin{array}{l}\text { People who cannot communicate with patients are not qualified to } \\
\text { be nurses. }\end{array}$ & 0.13 & 0.00 & 0.45 & -0.06 & -0.01 & 0.47 & -0.19 \\
\hline & VII: “Dependence” $(\alpha=0.68)$ & & & & & & & \\
\hline 22 & Doctors and superiors who always indicate are necessary. & 0.01 & -0.05 & 0.06 & 0.03 & -0.09 & 0.18 & 0.65 \\
\hline 24 & $\begin{array}{l}\text { If those who talk about their thoughts or feelings about work and can } \\
\text { provide advice are not working in the same location, I will be } \\
\text { troubled. }\end{array}$ & -0.01 & 0.04 & -0.09 & -0.09 & 0.02 & 0.10 & 0.57 \\
\hline 25 & One should work at the same pace as the other staff. & 0.07 & 0.27 & -0.02 & 0.09 & 0.04 & -0.25 & 0.57 \\
\hline 21 & Progress is difficult if there is no coworker one can depend on. & -0.01 & -0.16 & 0.29 & 0.12 & -0.01 & -0.08 & 0.46 \\
\hline
\end{tabular}




\begin{tabular}{ccccccccc} 
Continued & 1 & 2 & 3 & 4 & 5 & 6 & 7 \\
\hline Correlation between factors & 1.00 & 0.28 & 0.33 & 0.22 & 0.11 & 0.50 & 0.21 \\
1 & 0.28 & 1.00 & -0.06 & -0.01 & 0.11 & 0.35 & 0.23 \\
2 & 0.33 & -0.06 & 1.00 & 0.26 & 0.40 & 0.25 & 0.35 \\
3 & 0.22 & -0.01 & 0.26 & 1.00 & 0.22 & 0.19 & 0.21 \\
4 & 0.11 & 0.11 & 0.40 & 0.22 & 1.00 & 0.17 & 0.34 \\
5 & 0.50 & 0.35 & 0.25 & 0.19 & 0.17 & 1.00 & 0.22 \\
6 & 0.21 & 0.23 & 0.35 & 0.21 & 0.34 & 0.22 & 1.00 \\
\hline
\end{tabular}

$78.6 \%$ ), and 541 of them were valid and analysed (21 males and 520 females) of them were valid and analysed (valid response rate 77.4\%). For test-retest reliability, the survey was conducted after 4 weeks in 100 nurses who had taken part in the actual study. Ninety one nurses (3 males and 88 females) who responded to both the first and second surveys were included in the analysis set. Upon the test-retest in nurses working for 1 hospital which had been randomly selected, we put numbers on face sheets in addition to sex, age, department, final academic background, and marital status in order to identify individuals and asked them at the second time to fill out the survey forms with the same numbers so that they would be matched. The study was conducted between April 2009 and May 2009.

2) Scales used in this study

a) Individual attributes

Age, departments, and years of experience, sex was asked as it might affect the irrational belief in nursing [4] [10].

b) IBTN draft: The 5-point likert scale (5: feel exactly the same way; 1: do not feel the same way at all) was used; the higher the points, the stronger the irrational belief.

c) Measurement of burnout: The MBI (Maslach Burnout Inventory for Japanese version) was used. Kubo and Tao [15] modified the Maslach and Jackson's inventory scale [16]. This scale composes of 3 factors of "emotional exhaustion," "depersonalization," and "personal accomplishment", and consists of a total of 17 items, with 5 answer options for each, ranging from "always present" to "absent". "Personal achievement" referred to here is a reversal item, carrying the meaning of "a sense of reduced personal accomplishment." The higher the scores for "emotional exhaustion" and "depersonalization," the higher the tendency for burnout, whereas the lower the score for "personal accomplishment," the higher the tendency for burnout. Reliability and validity has been already verified.

d) Measurement of automatic thoughts: The Japanese version of Automatic Thoughts Questionnaire-Revised (ATQ-R) was used [17]. The questionnaire consists of a total of 40 items. It is a Japanese translation of a reconstituted 30-item, 4-factor questionnaire (self-expectation, problem avoidance, ethical blame, internal helplessness) concerning negative automatic thoughts [18], combined with 10 items of 1 factor related to positive automatic thoughts. In a study by Kodama et al., 4 factors, i.e., 15 items for negative evaluation of the future, 13 items for self-blame and 10 items for positive thinking, were extracted, and the questionnaire consisted of a total of 38 items. Automatic thoughts were measured on a 5-grade scale, ranging from "definitely yes" to "definitely no.” The higher the score, the stronger the automatic thoughts of the subscales. Cronbach's alpha coefficients ranged from 0.88 to 0.94 , reliability and validity has been verified.

e) Measurement of irrational beliefs: The Japanese Irrational Belief Test (JIBT-20) was used for the measurement of irrational beliefs [4]. This test is a shortened version of Matsumura's JIBT [19] (1991), and comprises 20 items, i.e., 4 items each for the following 5 factors: "self-expectation" (a person's belief that he or she must always be perfect), "dependence" (the belief that the person always needs to be instructed by someone else), "ethical blame" (the belief that people who commit a crime should be punished severely), "problem avoidance" (the belief that it is best to stay away from dangers and difficulties), and "helplessness" (the belief that it is natural to give up things that are going wrong, or to be confused under such situations). Irrational beliefs are measured on a 5-grade scale, ranging from "definitely yes" to "definitely no." The higher the score, the stronger 
the belief. Cronbach’s alpha coefficients ranged from 0.65 to 0.89 , reliability and validity has been verified.

3) Analysis

a) The mean value for each IBTN subscale was obtained to verify the descriptive statistics of IBTN.

b) In order to study cross validity, factor models were investigated by covariance structure analysis using the factors in the first survey as hypothetical factors. The compatibility of the models was examined using Goodness of Fit Index (GFI), Adjusted Goodness of Fit Index (AGFI) and Root Mean Square Error of Approximation (RMSEA).

c) In order to investigate construct validity, correlation coefficient of 5 JIBT-20 subscales, which seem to have similar construct, was calculated. In addition, the known-group method was used. It is expected that individuals with high scores for burnout also have high scores for irrational belief. Therefore, we calculated the median of the total score of MBI subscales and classified the subjects into the high burnout group and the low burnout group in order to perform analysis of variance with 7 IBTN subscales.

d) In order to investigate criterion-related validity, correlation coefficient between 3 ATQ-R subscales which measure automatic thoughts and $3 \mathrm{MBI}$ subscales which measure burnout, which were thought to have logical relations, was calculated.

e) In order to investigate test-retest reliability, correlation coefficient was calculated between the first survey and the second survey.

SPSS11.5 and AMOS5.0 were used for the statistical processing, and the level of significance was set as below $5 \%$.

4) Ethical considerations

The protocol of this study was approved by the Hiroshima University Ethics Committee, Japan. The objectives and procedures were explained in writing to the participants. They were then informed that their anonymity would be guaranteed, that their participation and withdrawal would be of their own free will, and that refusal to participate or withdrawing consent would not result in any negative consequence.

3. Results

1) A subject's basic attribute

The average age of the subjects was $33.81 \pm 8.68$ and the years of clinical experience was $10.90 \pm 8.24$ years ( 1 to 42 years). The gender composition of the subjects was 21 male and 518 female. The departments in which they work consist of internal medicine departments $(n=67)$, surgery departments $(n=91)$, outpatients $(n=98)$, operating rooms $(n=33)$, ICUs $(n=47)$, pediatrics wards $(n=38)$, obstetrics and gynecology departments $(n=$ 42), mixed departments $(n=100)$, community departments $(n=13)$ and other departments $(n=10)$.

2) Investigations on cross validity

In order to examine cross validity in IBTN factor structure, confirmatory factor analysis was performed using raw scores of IBTN 7 factors with 28 items (Figure 1). The factor loading was higher than 0.34 in all items. Since the loading of an absolute value between 0.30 and 0.40 is mostly considered as a cutoff point for factor loadings [20], a satisfactory value was acquired. Moreover, the compatibility index for the models was calculated as follows: $\chi^{2}=874.371, \mathrm{df}=329$, GFI $=0.89$, AGFI $=0.86$, and RMSEA $=0.05$. GFI and AGFI were judged satisfactory as the explanation rate of a model is considered good when the value is close to 1 . Moreover, if the RMSEA value is 0.05 or less, it is judged to be a good fit. On the other hand, if the RMSEA value is 0.10 or more, the goodness of fit is considered low and in that case, the model is not adopted [21]. These values were all adequate, suggesting that compatibility of data for the models was excellent. As for inter-factor correlations, the correlation coefficients were moderate or low ranged from 0.02 to 0.42 ; it was confirmed that each factor was discriminated. According to the results above, it was verified that IBTN factor structure has adequate cross validity.

3) Investigations into the construct validity

Correlation coefficients were calculated between subscales of JIBT-20 and IBTN in order to examine construct validity (Table 2). As a result, it was found that the correlation coefficients for "self-expectation", "problem avoidance", and "ethical blame" were moderate $(r=0.37, r=0.43$, and $r=0.31$, respectively; $p<0.01$ for all). The correlation for "helplessness" was $r=0.36$; a moderately positive correlation was observed $(p<0.01)$. The correlation coefficient for "dependence" was high $(\mathrm{r}=0.66, \mathrm{p}<0.01)$. Namely, these results were nearly consistent with the hypothesis. For "patient belief", which was considered specific to nurses, weak correlations were observed with JIBT-20 subscales "self-expectation", "dependence", and "ethical blame " $(r=0.13-0.27, p$ $<0.01$ ). In addition, for "self-inhibition", weak correlations were also seen with "self-expectation", "depen- 


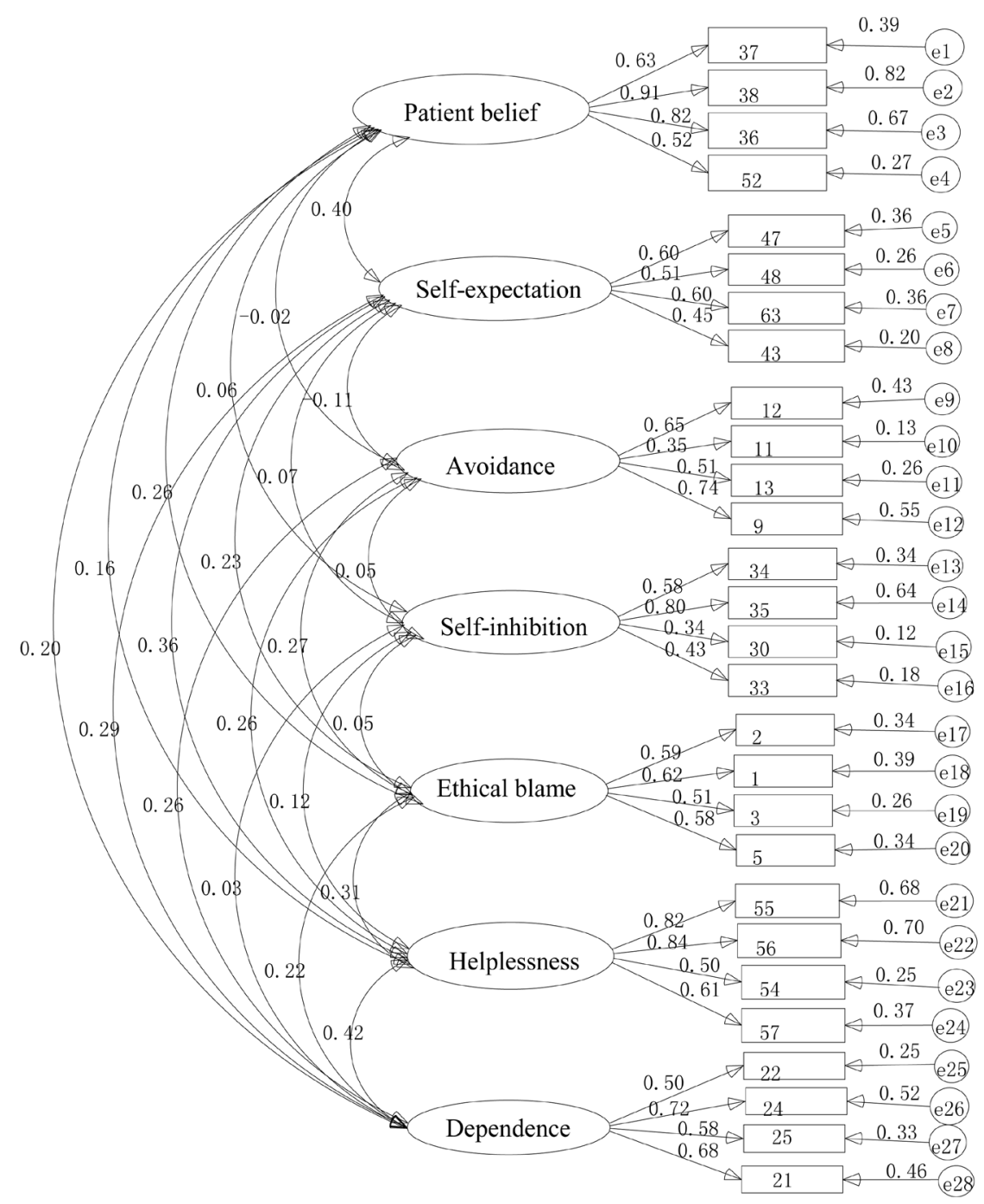

$\chi^{2}=874.371, \mathrm{df}=329, \mathrm{GFI}=0.89, \mathrm{AGFI}=0.86, \mathrm{RMSEA}=0.05$

Figure 1. Result of confirmation factor analysis of IBTN.

Table 2. Correlation coefficient of IBTN and JIBT-20.

IBTN

Self-expectation Dependence Ethical blame Avoidance Helplessness Self-inhibition Patient belief Sum

JIBT-20

\begin{tabular}{cllllllll} 
Self-expectation & $0.37^{* * *}$ & $0.28^{* *}$ & $0.26^{* *}$ & $0.08^{\text {n.s. }}$ & $0.20^{* *}$ & $0.14^{* * *}$ & $0.27^{* *}$ & $0.47^{* *}$ \\
Dependence & $0.13^{* *}$ & $0.66^{* *}$ & $0.13^{* *}$ & $0.27^{* *}$ & $0.34^{* *}$ & $0.11^{* *}$ & $0.13^{* *}$ & $0.48^{* *}$ \\
Ethical blame & $0.18^{* * *}$ & $0.24^{* *}$ & $0.31^{* *}$ & $0.09^{*}$ & $0.14^{* *}$ & $0.01^{\text {n.s. }}$ & $0.16^{* *}$ & $0.31^{* *}$ \\
Avoidance & $-0.09^{*}$ & $0.19^{* *}$ & $0.16^{* *}$ & $0.49^{* *}$ & $0.15^{* *}$ & $0.23^{* *}$ & $0.06^{\text {n.s. }}$ & $0.32^{* *}$ \\
Helplessness & $0.02^{\text {n.s. }}$ & $0.34^{* *}$ & $0.20^{* *}$ & $0.33^{* *}$ & $0.36^{* *}$ & $-0.02^{\text {n.s. }}$ & $0.01^{\text {n.s. }}$ & $0.31^{* *}$ \\
Sum & $0.55^{* *}$ & $0.53^{* *}$ & $0.54^{* *}$ & $0.40^{* *}$ & $0.64^{* *}$ & $0.33^{* *}$ & $0.60^{* *}$ & $0.60^{* *}$ \\
\hline
\end{tabular}

${ }^{*} \mathrm{p}<0.05 ;{ }^{* *} \mathrm{p}<0.01 ;{ }^{\text {n.s. }}$ non significant. 
dence", "ethical blame “, and "problem avoidance" $(r=0.11-0.23, p<0.01)$. The weakness of correlations with "patient belief" and "self-inhibition" can be explained by the fact that these are the constructs which are independent of other concepts. As a whole, the values of $r=0.31-0.64$ were obtained for JIBT-20 and IBTN.

Upon investigations of construct validity with the known-group method, the subjects were classified into the high group and the low group using the median values for burnout at first, and then the scores were compared. The results are presented in Tables 3-5. Regarding "emotional exhaustion", the scores were significantly higher for "avoidance", "ethical blame", "helplessness", and "dependence" in the group with high "emotional exhaustion" compared to the low group ( $<<0.01$ for all). Regarding depersonalization, the scores were significantly higher for "self-expectation" in the low group compared to the high group $(\mathrm{p}<0.01)$, while for "avoidance" $(\mathrm{p}<$ $0.01)$, "helplessness" ( $p<0.01)$, “dependence" ( $<<0.05)$, and "ethical blame" $(p<0.05)$, the scores were significantly higher in the high group than in the low group. Regarding "personal feeling of achievement", the scores were higher for "self-expectation" and "ethical blame" in the high group compared to the low group, while for "avoidance", the scores were higher in the low group than in the high group ( $<<0.01$ for all) (F-values are on Tables 4-6, df was [1537] for all).

According to the results above, it was suggested that the scale of IBTN has a degree of construct validity, though it is not sufficient.

4) Investigations on criterion-related validity

Ohue et al. [3] have reported that irrational beliefs which affect burnout were "helplessness", "problem avoidance", and "dependence". In addition, Fukui et al. [22] have revealed associations between the irrational beliefs and automatic thoughts or feelings and reported that the irrational beliefs such as "helplessness", "problem avoidance", and "dependence" affect the automatic negative thoughts and induce depression. Hence, it was thought that the criterion-related validity of IBTN could be examined by calculating correlation coefficients with ATQ-R subscales which measure automatic thoughts and with MBI subscales measuring burnout.

Table 3. The difference of IBTN in the low group and high group of emotional exhaustion.

\begin{tabular}{|c|c|c|c|c|c|}
\hline & \multicolumn{2}{|c|}{ Low group $(\mathrm{N}=262)$} & \multicolumn{2}{|c|}{ High group $(\mathrm{N}=279)$} & \multirow[b]{2}{*}{$\mathrm{F}$} \\
\hline & M & SD & M & $\mathrm{SD}$ & \\
\hline Patient belief & 11.52 & 3.16 & 11.45 & 3.11 & $0.66^{\text {n.s. }}$ \\
\hline Self-expectation & 13.55 & 2.31 & 13.50 & 2.57 & $0.07^{\text {n.s. }}$ \\
\hline Avoidance & 9.93 & 2.40 & 11.49 & 2.60 & $52.35^{* *}$ \\
\hline Self-inhibition & 10.27 & 2.21 & 10.24 & 2.16 & $0.02^{\text {n.s. }}$ \\
\hline Ethical blame & 11.46 & 2.55 & 11.86 & 2.27 & $3.64^{* *}$ \\
\hline Helplessness & 11.31 & 2.44 & 11.97 & 2.69 & $8.85^{* *}$ \\
\hline Dependence & 13.65 & 2.66 & 14.59 & 2.59 & $17.29^{* *}$ \\
\hline
\end{tabular}

${ }_{\mathrm{p}}^{*}<0.05 ;{ }^{* *} \mathrm{p}<0.01 ;{ }^{\text {n.s. }}$ non significant.

Table 4. The difference of IBTN in the low group and high group of depersonalization.

\begin{tabular}{|c|c|c|c|c|c|}
\hline & \multicolumn{2}{|c|}{ Low group $(\mathrm{N}=311)$} & \multicolumn{2}{|c|}{ High group $(\mathrm{N}=210)$} & \multirow[b]{2}{*}{$\mathrm{F}$} \\
\hline & M & SD & M & SD & \\
\hline Patient belief & 11.48 & 3.11 & 11.50 & 3.18 & $0.00^{\text {n.s. }}$ \\
\hline Self-expectation & 13.73 & 2.27 & 13.20 & 2.68 & $6.30^{* *}$ \\
\hline Avoidance & 10.06 & 2.38 & 11.80 & 2.64 & $62.41^{* *}$ \\
\hline Self-inhibition & 10.27 & 2.22 & 10.24 & 2.13 & $0.01^{\text {n.s. }}$ \\
\hline Ethical blame & 11.51 & 2.47 & 11.91 & 2.30 & $3.53^{*}$ \\
\hline Helplessness & 11.40 & 2.49 & 12.04 & 2.70 & $8.04^{* *}$ \\
\hline Dependence & 13.97 & 2.64 & 14.40 & 2.68 & $3.49^{*}$ \\
\hline
\end{tabular}

${ }^{*} \mathrm{p}<0.05 ;{ }^{* *} \mathrm{p}<0.01 ;{ }^{\text {n.s. }}$ non significant. 
Table 5. The difference of IBTN in the low group and high group of personal accomplishment.

\begin{tabular}{|c|c|c|c|c|c|}
\hline & \multicolumn{2}{|c|}{ Low group $(\mathrm{N}=266)$} & \multicolumn{2}{|c|}{ High group $(\mathrm{N}=275)$} & \multirow[b]{2}{*}{$\mathrm{F}$} \\
\hline & M & SD & M & SD & \\
\hline Patient belief & 11.30 & 3.10 & 11.66 & 3.16 & $1.72^{\text {n.s. }}$ \\
\hline Self-expectation & 13.15 & 2.47 & 13.89 & 2.37 & $12.54^{* *}$ \\
\hline Avoidance & 11.04 & 2.65 & 10.44 & 2.57 & $7.01^{* *}$ \\
\hline Self-inhibition & 10.23 & 2.14 & 10.29 & 2.23 & $0.11^{\text {n.s. }}$ \\
\hline Ethical blame & 11.35 & 2.48 & 11.97 & 2.31 & $9.32^{* *}$ \\
\hline Helplessness & 11.75 & 2.59 & 11.55 & 2.59 & $0.77^{\text {n.s. }}$ \\
\hline Dependence & 14.07 & 2.75 & 14.20 & 2.58 & $0.31^{\text {n.s. }}$ \\
\hline
\end{tabular}

${ }^{*} \mathrm{p}<0.05 ;{ }^{* *} \mathrm{p}<0.01 ;$. ${ }^{\text {..s. }}$ non significant.

Table 6. Correlation coefficient of IBTN and ATQ-R MBI.

\begin{tabular}{|c|c|c|c|c|c|c|c|}
\hline & \multicolumn{7}{|c|}{ IBTN } \\
\hline & Self-expectation & Dependence & $\begin{array}{l}\text { Ethical } \\
\text { blame }\end{array}$ & Avoidance & Helplessness & Self-inhibition & Patient belief \\
\hline \multicolumn{8}{|l|}{ ATQ-R } \\
\hline Negative evaluation of the future & $0.01^{\text {n.s. }}$ & $0.03^{\text {n.s. }}$ & $0.05^{\text {n.s. }}$ & $0.13^{* *}$ & $0.30^{* *}$ & $0.02^{\text {n.s. }}$ & $0.02^{\text {n.s. }}$ \\
\hline Negative self-evaluation & $0.06^{\text {n.s. }}$ & $0.14^{* *}$ & $0.08^{\text {n.s. }}$ & $0.16^{* *}$ & $0.35^{* *}$ & $0.03^{\text {n.s. }}$ & $0.05^{\text {n.s. }}$ \\
\hline Positive thinking & $0.12^{* *}$ & $-0.03^{\text {n.s. }}$ & $0.03^{\text {n.s. }}$ & $-0.17^{* *}$ & $-0.13^{* *}$ & $0.08^{\text {n.s. }}$ & $0.09^{*}$ \\
\hline \multicolumn{8}{|l|}{ MBI } \\
\hline Emotional exhaustion & $-0.03^{\text {n.s. }}$ & $0.17^{* *}$ & $0.06^{\text {n.s. }}$ & $0.35^{* *}$ & $0.17^{* *}$ & $-0.05^{\text {n.s. }}$ & $-0.04^{\text {n.s. }}$ \\
\hline Depersonalization & $-0.17^{* *}$ & $0.05^{\text {n.s. }}$ & $0.09^{*}$ & $0.39^{* *}$ & $0.12^{* *}$ & $-0.05^{\text {n.s. }}$ & $-0.02^{\text {n.s. }}$ \\
\hline Personal accomplishment & $0.17^{* *}$ & $0.09^{*}$ & $0.13^{* *}$ & $-0.12^{* *}$ & $-0.07^{\text {n.s. }}$ & $0.04^{\text {n.s. }}$ & $0.07^{\text {n.s. }}$ \\
\hline
\end{tabular}

${ }^{*} \mathrm{p}<0.05 ;{ }^{* *} \mathrm{p}<0.01$; ${ }^{\mathrm{n} . \mathrm{s}}$.non significant.

Significant correlation coefficients were obtained for "problem avoidance" and "helplessness" with "Negative evaluation of the future", "Negative self-evaluation", and "positive thinking" $(p<0.01)$. Moreover, weak correlation coefficients were seen between "patient belief" and "positive thinking" ( $<<0.05)$, "self-expectation" and "positive thinking" ( $p<0.01$ ), and "dependence" and "Negative self-evaluation" ( $p<0.01)$. No significant correlation was observed for "ethical blame" and "self-inhibition" with any items.

When correlation coefficients were calculated with burnout in MBI, it was hypothesized that positive correlation coefficients would be obtained with "emotional exhaustion" and "depersonalization", and negative correlation would be seen with "personal feeling of achievement". According to the results, "avoidance" was correlated with "emotional exhaustion" ( $\mathrm{p}<0.01$ ), "depersonalization" $(\mathrm{p}<0.01)$ and "personal feeling of achievement" ( $\mathrm{p}$ $<0.01$ ). Moreover, weak or moderate correlation coefficients were observed for "helplessness" with "emotional exhaustion" ( $\mathrm{p}<0.01$ ) and "depersonalization" ( $\mathrm{p}$ <.01) (Table 6). Considering the above, it seemed that the values obtained were satisfactory, although these were never adequate, suggesting that criterion-related validity was confirmed to some extent.

5) Test-retest reliability

The values of $r=0.36-0.64$ were obtained for IBTN test-retest reliability (Table 7). Usually, the fiducial point of test-retest reliability sufficiently fulfills the conditions, in case the value exceeds 0.70 [20]. Therefore, the above score was low. Mori et al. [4] also reported that the values of $r=0.31-0.63$ were obtained after an interval of 18 weeks, suggesting that the test-retest reliability of IBTN was similar to that observed with the original JIBT-20. This time period (between April and May) might also involve a big psychological change in nurses due to factors, including the movement of personnel and training of newcomer nurses. Therefore, the testretest reliability was evaluated after taking the time interval factor into consideration. 
Table 7. A test-retest correlation coefficient.

\begin{tabular}{cl}
\hline & $\mathrm{N}=91$ \\
\hline Patient belief & $0.58^{* *}$ \\
Self-expectation & $0.36^{* *}$ \\
Avoidance & $0.62^{* *}$ \\
Self-inhibition & $0.64^{* *}$ \\
Ethical blame & $0.59^{* *}$ \\
Helplessness & $0.56^{* *}$ \\
Dependence & $0.37^{* *}$ \\
Sum & $0.64^{* *}$ \\
\hline
\end{tabular}

${ }^{* *} \mathrm{p}<0.001$.

\section{Total Consideration}

\section{1) Reliability and validity of IBTN}

Reliability was examined by Cronbach's $\alpha$ coefficient and test-retest reliability was calculated. The reliability coefficients were above the standard level in both surveys, suggesting that reliability for IBTN was verified.

On the other hand, for validity, question items were prepared by researchers who used to have clinical nursing experiences. The items were created based on the previous studies and agreed by 6 experts according to the item evaluation standard. The results suggest that IBTN has content validity. The construct validity was examined by significant correlations with JIBT-20 and the known-group method. The results revealed that the high burnout group had stronger irrational beliefs in "ethical blame”, "problem avoidance”, "helplessness”, and "dependence” compared to the low burnout group, and with regard to criterion-related validity, significant correlations were observed with MBI and ATQ-R, though no correlation was found for "patient belief" and "self-inhibition". In the above mentioned criterion-related validity, there was no correlation with MBI factors; these were not the irrational beliefs which directly affect burnout. It is thought that these items have content validity. Furthermore, a confirmatory factor analysis was performed using the Survey 1 factors as hypothesis. According to the results, the relationship between IBTN factors and each item, and the factor loadings were statistically plausible. At the same time, cross validity was examined. Hence, IBTN is considered as a scale which has consistent reliability and validity.

2) Investigations on IBTN factors and items

IBTN was created based on JIBT-20 introduced by Mori et al. [4]. The results of exploratory factor analysis indicated that this scale consisted of 7 subscales including "patient belief", "self-expectation", "avoidance", "self-inhibition", "ethical blame", "helplessness", and "dependence”. For these subscales, factors were extracted as in hypothesis. In this study, we performed exploratory factor analyses for 4 times, but the factor structure and items did not change at all. Considering that the factor structure and items were compatible somehow, it is surmised that IBTN is a scale having stability of the factor structure.

Matsumura [19] reported there is an association between irrational belief and inappropriateness and revealed that neurotic patients have more irrational beliefs than healthy individuals in terms of internal helplessness, dependence, problem avoidance, external helplessness, and self-expectation. In addition, Mori et al. [4] compared psychosomatic patients and healthy individuals and reported that the scores were significantly higher for dependence and helplessness in the clinical group than in the healthy individuals. According to the results of this study, positive significant correlation was observed between emotional exhaustion and "avoidance", "helplessness" and "dependence", and the scores were significantly higher in the high burnout group. Namely, it is suggested that these irrational beliefs could affect burnout as neurotic or psychosomatic conditions and that IBTN is a scale which is clinically significant as an evaluation scale for the purpose of reducing burnout in nurses. These irrational beliefs are "social know-how that one has to adopt inevitably for others and society though it is not desirable" [19]. It seems that nurses fall into burnout due to these beliefs which they have to adopt inevitably when working as a nurse, although these are never desirable. Hence, it was suggested that alteration of these irrational beliefs may lead to reduction of burnout in nurses.

The scores for "ethical blame" were likely to be high in the high burnout group and for "self-expectation" 
these were likely to be higher in the low burnout group. These irrational beliefs "represent desirable idealistic beliefs of self or others for the society, and these beliefs seem to be associated with positive evaluations of the person” [19]. In addition, Otani et al. [23] have reported that there are two aspects, which are positively and negatively associated with mental health, in perfectionism and defined that the former is "an aspect that one pursues perfection as a goal" and the latter is "an aspect that one does not accept imperfection which occurred as a consequence". In fact, "self-expectation" was found to be negatively associated with burnout when the criterion-related validity was investigated. Namely, "self-expectation" of this scale may be equivalent to the former described by Otani, et al. [23]. Also, Nakano [24] have listed "mean or negative attitudes, irritation, and anger toward colleagues," as actual symptoms of burnout. In other words, the more the nurses fall into burnout, the higher the scores become for "ethical blame", meaning that the scores become high for "ethical blame" since they are in the burnout condition. Considering all the above, it was suggested that IBTN consists of factors or items which have been proven by the previous studies.

3) Clinical significance of IBTN

This is a scale to measure personal internal characteristics known as personal irrational beliefs and is expected to create clinical significance as an index to evaluate effects on interventions to reduce burnout in nurses.

IBTN allows us to measure irrational beliefs in nursing practice; especially, the factors such as "helplessness", "avoidance", and "dependence" are irrational beliefs which show positive association with burnout. In other words, it was suggested that alteration of these beliefs might reduce burnout and even resignation from the job. In terms of application of this scale in the clinical settings, the nurses become aware of or recognize their irrational beliefs by filling out IBTN and evaluate themselves. This may help changing their recognition. Furthermore, it can be used for evaluations of cognitive behavioral approaches. Therefore, it is thought that IBTN is useful to assess irrational beliefs in the nursing job when interventions are performed in order to reduce burnout in nurses.

4) Restrictions in this study and future goals

In this study, indices of automatic thoughts and burnout were used to create an effective evaluation index in order to reduce burnout in nurses. Ohue et al. [3] and Fukui et al. [22] have reported that there are associations between irrational beliefs and automatic thoughts or burnout. However, for "patient belief" and "self-inhibition", no correlation was observed with external criteria. Further investigations are necessary in the future for validity of these factors. Then, efficacy of IBTN, as an index to confirm reduction effects on burnout in nurses, needs to be verified by changing their cognitions with the cognitive behavioral therapy.

\section{References}

[1] Ellis, A. (1962) Reason and Emotion in Psychotherapy. Lule Stuart, New York.

[2] Balever, P. (2001) Professional Nursing Burnout and Irrational Thinking. Journal for Nurses in Staff Development, 17, 264-271. http://dx.doi.org/10.1097/00124645-200109000-00012

[3] Ohue, T., Moriyama, M. and Nakaya, T. (2011) Examination of a Cognitive Model of Stress, Burnout, and Intention to Resign for Japanese Nurses. Japan Journal of Nursing Science, 8, 76-86.

http://dx.doi.org/10.1111/j.1742-7924.2010.00161.x

[4] Mori, H., Hasegawa, K., Ishikuma, T., et al. (1994) Development of Irrational Belief Scale (JIBT-20). Human Science Research, 3, 43-58.

[5] Sakano, Y. (1995) Cognitive Behavior Therapy. Nihonhyouronsha, Tokyo.

[6] Kawamura, S. and Kokubun, Y. (1996) Investigation about Belief of an Elementary School Teacher. The Japanese Journal of Counseling Science, 29, 44-54.

[7] Matsumaru, A., Omori, M. and Akamatsu, R. (2008) Reliability and Validity of the Irrational Eating Belief Scale (IEBS). The Japanese Society of Nutrition and Dietetics, 66, 141-148. http://dx.doi.org/10.5264/eiyogakuzashi.66.141

[8] Osberg, T.M., Poland, D., Aguayo, G. and MacDougall, S. (2008) The Irrational Food Beliefs Scale: Development and Validation. Eating Behaviors, 9, 25-40. http://dx.doi.org/10.1016/j.eatbeh.2007.02.001

[9] Tomotake, M., Okura, M., Taniguchi, T. and Ishimoto, Y. (2002) Traits of Irrational Beliefs Related to Eating Problems in Japanese College Women. The Journal of Medical Investigation, 49, 51-55.

[10] Ito, H., Kabasawa, K. and Yosimoto, T. (2008) Approach to Make Scale of Irrational Belief for Sport: Examination of Sex Differences, Reliability and Validity. Journal of Physical Education, Health and Sport Sciences, Nihon University, 42, 69-77. 
[11] Honda, M., Isiguma, T. and Arai, K. (2005) Development of Junior High School Student’s Personal-Relations Belief Scale (1). Bulletin of Counseling and School Psychology, 43, 11-17.

[12] Matumoto, S., Kumano, H., Sakano, Y. and Nozoe, S. (2001) Development of the Beliefs Related to Shape and Diet Scale: Investigation of Cognitive Aspect on Eating Disorders. Japanese Journal of Psychosomatic Medicine, 41, 335342.

[13] Higashiguchi, K., Mori, H., Miura, K., et al. (1998) The Job Stressor of the Clinical Nurse-Considering the Psychological Characteristics and Measurement Scale Development Work Stressor. Health Psychology Research, 11, 64-72.

[14] Doi, K. and Hashiguchi, H. (2000) The Relationship between Irrational Belief and Mental Health in Junior HighSchool Teachers. The Japanese Journal of Health Psychology, 13, 23-30. http://dx.doi.org/10.11560/jahp.13.1_23

[15] Tao, M. and Kubo, M. (1992) Measurement of Burnout. Japanese Psychological Review, 35, 361-376.

[16] Maslach, C. and Jackson, S.E. (1981) The Measurement of Experienced Burnout. Journal of Organizational Behavior, 2, 99-113. http://dx.doi.org/10.1002/job.4030020205

[17] Kodama, M., Katayanagi, H., Shimada, H. and Sakano, Y. (1994) The Relationships among Stress Coping with Automatic Thoughts, State of Anxiety, and Depressive Symptoms in College Students. The Human Sciences, Human Research Center, Waseda University, 7, 14-26.

[18] Hollon, S.D. and Kendall, P.C. (1980) Cognitive Self-Statements in Depression: Development of an Automatic Thoughts Questionnaire. Cognitive Therapy and Research, 4, 383-395. http://dx.doi.org/10.1007/BF01178214

[19] Matsumura, C. (1991) The Development of the Japanese Irrational Belief Test (JIBT). Japanese Journal of Psychology, 62, 106-113.

[20] Polit, D.F. and Beck, C.T. (2010) Essentials of Nursing Research: Appraising Evidence for Nursing Practice. 7th Edition, Wolters Kluwer Health/Lippincott Williams \& Wilkins, Philadelphia.

[21] Toyota, H. (1998) Covariance Structure Analysis: Beginners Guide. Asakura Publishing, Tokyo.

[22] Fukui, I. and Sakano, Y. (2000) The Relationship among Irrational Beliefs, Automatic Thoughts and Depressive/Anxious Mood. Human Welfare Studies, 3, 1-12.

[23] Otani, Y. and Aketa, Y. (1999) The Relationship of "Self-Oriented Perfectionism” to Psychological Well-Being: A Study Based on Psychological Bad-Health Occurrence Model. The Psychological Report of Sophia University, 23, 61-72.

[24] Nakano, K. (2005) Stress Management. Kongoshupan, Tokyo. 